\title{
Dieta alimenticia en la provincia de Caracas en la segunda mitad del siglo XVIII: problemas y resultados cuantitativos
}

\author{
Jaime Torres Sánchez \\ Universidad de los Andes, Venezuela
}

En este artículo se presentan los resultados del análisis cuantitativo de un documento inédito elaborado por don Fernando de Lovera, en Caracas, el 22 de octubre de 1752, y de otro atribuido al doctor Agustín Marón, fechado en Caracas en 1775. Se examinan algunos problemas técnicos planteados por los cálculos, se presentan nuevas tablas de valores para el examen metrológico y tablas de consumo de alimentos y de población corregidas.

PALABRAS CLAVE: análisis cuantitativo, alimentos, metrología, época colonial.

This article presents results of quantitative analysis done on an unpublished document written by don Fernando de Lovera in Caracas on October 22, 1752, and another attributed to doctor Agustín Marón, Caracas, 1775. This article gives some technical problems stated by calculations, and it presents new tables of values for metrological analysis and corrected tables of food consumption and population.

KEYWORDS: quantitative analysis, foods, metrology, colonial era.

El análisis de un documento inédito firmado por el regidor don Fernando de Lovera y fechado en Caracas el 22 de abril de 1752, elaborado con el propósito de calcular el consumo de víveres en la provincia, ${ }^{1}$ proporciona valiosa información que permite afinar métodos, reelaborar cálculos que posibilitan la comparación con similar información de un documento publicado, fechado en $1775,{ }^{2}$ y mejorar los resultados alcanzados en el conocimiento de la alimentación colonial. ${ }^{3}$ En este artículo se examinarán algunos problemas técnicos del cálculo, se presentarán nuevas Tablas de Equivalencia y algunos resultados cuantitativos respecto al consumo de alimentos y cifras de población de la Provincia de Caracas, en 1751 y 1775.

1 Véase el apéndice final.

2 Marón, A.: "Relación Histórico-Geográfica de la Provincia de Venezuela. 1775", en Arellano Moreno, A. (compilador): Documentos para la Historia Económica Colonial. Viajes $e$ Informes, Caracas, 1970, págs. 411-474.

3 Torres S., Jaime: "Consumo de carne y nutrición. Aspectos de su evolución histórica en Venezuela: 1609-1873”, Anuario de Estudios Americanos, LIV-1, Sevilla, 1997, págs. 65-85. 


\section{Algunos problemas de método: metrología colonial e historia de la alimentación}

Un problema central para el estudio de la alimentación colonial está referido a las unidades antiguas de medición de peso y volumen, tanto en sus variabilidades regionales como en sus equivalencias con las unidades del Sistema Métrico Decimal (SMD). ${ }^{4}$ Dada la importancia de tales valores para los cálculos de nutrientes, parece necesario especificar los razonamientos que permiten deducir algunas equivalencias implícitas en las dos fuentes trabajadas en este artículo que atribuyen cantidades de alimentos consumidos a la población. Un criterio importante para establecer las correspondencias entre valores antiguos y modernos es ubicar la equivalencia de las primeras respecto a 'libras', una unidad para la cual su valor en el SMD es bastante estable.

El documento de 1752 fue elaborado por el regidor del Cabildo de Caracas D. Fernando Antonio de Lovera y Otáñez, por orden del entonces gobernador de Venezuela D. Felipe Ricardos (ver el apéndice final). En sus folios cuatro y cinco se establecen las siguientes equivalencias para el maíz, casabe y 'granos' tales como frijoles, caraotas, arroz, chícharos y arvejas: 1 fanega $=12$ almudes $=4$ cuartillas, 1 cuartilla $=3$ almudes y 1 arroba $=25$ libras. Asimismo, en el folio cinco, señala para el cacao: 1 fanega $=110$ libras y 1 libra $=16$ onzas; $y$ en el folio tres se deduce para la carne la relación de 1 arroba $=25$ libras. Estas equivalencias se mantendrían en la Real Orden de 1801 que, por primera vez, modificó el sistema de pesas y medidas colonial en un intento de simplificación, excepto para la arroba que se equiparó a 15 libras, ${ }^{5}$ estableciéndose que la equiparación de la libra a 16 onzas correspondía a "las cosas que se compren y vendan al peso". ${ }^{6}$

El documento de 1775 también utiliza el almud como unidad de medida para el maíz y los granos, "arroz, frijoles, caraotas, quinchonchos, judías, arvejas, guisantes ...garbanzos", estableciendo la relación general de 1 fane-

4 Para un recuento de los problemas del tránsito del sistema colonial de pesos y medidas al sistema métrico decimal véase Landaeta Rosales, M.: Riqueza circulante en Venezuela, Caracas, 1903. Para Tablas de Equivalencia ver: Veloz Goiticoa, N.: Venezuela, 1904, pág. 588; Almenar, Carlos G.: Consultor Métrico-Decimal, Caracas, 1925, págs. 1-133; Rodríguez Castillo, L.: Las unidades y los sistemas de medidas pre-métricas en Venezuela, Caracas, 1983.

5 Landaeta, Riqueza..., págs. 219-220.

6 Landaeta, Riqueza..., pág. 221. 
ga $=12$ almudes y 1 almud $=12,0012$ libras, específicamente para los granos. ${ }^{7}$ Este último valor está implícito y se ha deducido con el siguiente razonamiento: si el número de habitantes multiplicado por 4 es igual al consumo de granos en almudes, el consumo per cápita anual es de cuatro almudes en el documento, al aplicar la equivalencia 1 fanega $=12$ almudes, el consumo calculado en fanegas debe ser igual al consumo documental en fanegas y libras. Entonces, los decimales del primer miembro de la igualdad, que se expresa en fanegas y almudes, deben ser iguales a las libras del segundo miembro. Una simple división permite calcular las libras por almud. Se puede deducir que, para los granos, una fanega era igual a 144 libras. Por ejemplo, el número de personas para 'Cordillera y valles del Tuy con sus pueblos' es de 7.015. Así,

$$
\begin{aligned}
7.015 \times 4 & =28.060 \text { almudes } \\
\text { como } 1 \text { fanega } & =12 \text { almudes } \\
\text { entonces } 28.060 & =2.338,3333 \text { fanegas } \\
\text { pero } 2.338,3333 & =2.338 \text { fanegas, } 4 \text { libras } \\
\text { y } 0,3333 & =4,0 \\
\text { entonces } 1 \text { almud } & =12,0012 \text { libras y } 1 \text { fanega }=144 \text { libras }
\end{aligned}
$$

Para el casabe establece que 1 arroba $=22,8125$ libras; $; 8$ para el cacao, 1 libra $=15,8696$ onzas; ${ }^{9}$ el papelón, 1 arroba $=25$ libras, obtenido por la fórmula: 50 libras $\times$ número de habitantes $=$ consumo en libras $/$ consumo documental en arrobas; ${ }^{10}$ la sal, 1 fanega $=12$ almudes; y la carne, 1 arroba $=393,07692$ onzas. ${ }^{11}$ Como el autor establece esta relación entre onzas y arrobas, al aceptarse que la arroba es igual a 25 libras se tendría que 1 libra $=15,723077$ onzas y 1 onza $=29,26$ gramos.

Está bien establecido que en el período colonial la fanega de cacao equivalía a 110 libras, pero se desconoce la equivalencia explícita de las fanegas a libras en los otros productos. Durante el siglo XIX la equivalencia a libras de todos estos productos tendió a variar según las regiones, pero es probable que tal situación no haya sido diferente en la segun-

7 Marón, "Relación"..., págs. 448, 451 y 452.

8 Marón, "Relación"..., págs. 447 y 451.

9 Marón, "Relación"..., pág. 448.

10 Marón, "Relación”..., págs. 448 y 451.

11 Marón, “Relación”..., págs. 447 y 449. 
da mitad del siglo XVIII. Esto introduce dificultades si se trata de convertir estas unidades de medida a valores propios al sistema métrico decimal. Debe considerarse que un autor ha establecido diecinueve equivalencias distintas en libras para la fanega de maíz en todo el territorio nacional durante el siglo XIX, con similar variabilidad en los distintos tipos de granos. ${ }^{12}$ Cuando la fanega de un producto es expresada en libras en la documentación se hace más fácil su conversión a gramos, puesto que esta unidad 'antigua' de medida se expresó en la práctica del siglo XIX con valores muy cercanos al de su definición legal de 460 gramos en $1873 .{ }^{13}$ Las anteriores informaciones pueden resumirse en el Cuadro siguiente.

\section{CUADRO N..$^{\circ}$}

RELACIONES DE EQUIVALENCIA DOCUMENTALES SEGÚN PRODUCTOS

EN LA SEGUNDA MITAD DEL SIGLO XVIII. PROVINCIA DE CARACAS

\begin{tabular}{|c|c|c|}
\hline Productos & 1751 & 1775 \\
\hline Maíz & $\begin{array}{l}1 \text { fanega }=12 \text { almudes } \\
1 \text { arroba }=25 \text { libras }\end{array}$ & 1 fanega $=12$ almudes \\
\hline Granos & $\begin{array}{l}1 \text { fanega }=12 \text { almudes } \\
1 \text { arroba }=25 \text { libras }\end{array}$ & $\begin{array}{l}1 \text { fanega }=12 \text { almudes } \\
1 \text { almud }=12,0012 \text { libras }\end{array}$ \\
\hline Casabe & 1 arroba $=25$ libras & 1 arroba $=22,8125$ libras \\
\hline Cacao & $\begin{aligned} 1 \text { fanega } & =110 \text { libras } \\
1 \text { libra } & =16 \text { onzas }\end{aligned}$ & 1 libra $=15,8696$ onzas \\
\hline Carne & 1 arroba $=25$ libras & $\begin{aligned} 1 \text { arroba } & =393,0769 \text { onzas } \\
1 \text { arroba } & =25 \text { libras } \\
1 \text { libra } & =15,7231 \text { onzas } \\
1 \text { onza } & =29,26 \text { gramos }\end{aligned}$ \\
\hline Papelón & & $\begin{aligned} 1 \text { arroba } & =25 \text { libras } \\
1 \text { libra } & =18,25 \text { onzas }\end{aligned}$ \\
\hline
\end{tabular}

12 Almenar, Consultor..., págs. 45, 123-133.

13 Landaeta, Riqueza..., pág. 233. 
Un aspecto importante de estas equivalencias es que si la fanega se mantuvo invariable en su relación de $1: 12$ con el almud en los períodos colonial y post-colonial, variando su expresión en libras durante el siglo XIX, querría decir que fue la equivalencia entre almud y libra la que experimentó variaciones. El problema de convertir el almud y la fanega al SMD, en ausencia de una conversión documental a libras, puede enfrentarse sobre la base de algunas evidencias indirectas para un bien alimenticio importante como el maíz. Ambos textos proporcionan una información coincidente respecto a cuantas arepas podían obtenerse de un almud de maíz.

El autor del documento de 1752 señala en el folio cuatro que: "es evidente que de un almud de maíz producen 33 panes y cada individuo consume al día 3 de estos", refiriéndose a 'arepas'. En 1775, a su vez, se señala que "del almud de maíz sacan en la mayor parte de los pueblos 32 arepas medianitas" $" 14$ consumiéndose dos diarias por persona. Si se sabe el peso de cada arepa en libras o en unidades actuales se podría conocer la equivalencia de la fanega y el almud a gramos.

Para 1839 se dispone de una evaluación del peso de estas arepas: "puede comer una persona durante una año, a razón de cuatro arepas o panes diarios de media libra cada uno". ${ }^{15}$ Otro autor indica en 1875 que "la población consume el pan de maíz, a razón de cuatro arepas diarias, con un peso entre las cuatro de medio kilo, más o menos". ${ }^{16}$

Los datos organizados para su análisis son los siguientes:

\begin{tabular}{cccc} 
Año & $\begin{array}{c}\text { Peso de una } \\
\text { arepa }(\text { grs })\end{array}$ & $\begin{array}{c}\text { Consumo } p / c \text { diario } \\
\text { de arepas }\end{array}$ & $\begin{array}{c}\text { Consumo } p / c \text { diario } \\
\text { de maíz }(\text { grs })\end{array}$ \\
\hline 1839 & 230 & 4 & 920 \\
1875 & 125 & 4 & 500
\end{tabular}

Un peso de 230 gramos por arepa en 1839 no parece excesivo si se considera que en la segunda mitad del siglo XX en áreas fuertemente tradicionales de la zona oriental costera todavía la arepa cotidiana podía

14 Marón, "Relación"..., pág. 447.

15 Codazzi, Agustín: Resumen de la Geografía de Venezuela, Caracas, 1940, vol. I, pág. 165.

16 Tejera, Miguel: Venezuela pintoresca e ilustrada, París, 1875, vol. I, pág. 285. 
alcanzar ese peso. Podría ser éste el peso propio a una arepa 'grande'. ${ }^{17}$ Considerando la estabilidad del número documental de arepas consumido diariamente por una persona, podría deducirse que la variación en el peso de las unidades dependía de su tamaño. En 1775 las dos arepas diarias per cápita eran consideradas de tamaño como "medianitas". Por tanto, es posible que en la segunda mitad del siglo XVIII el peso de la arepa considerada por los dos documentos se acercara más al promedio de los valores del cuadro antecedente: unos 178 gramos por unidad. Adviértase también que en 1750 y 1775 la variación en el número de arepas por almud fue muy escasa, lo que podría indicar que el tamaño varió muy poco. Si se consideran los 178 gramos como el valor medio de una arepa 'medianita', se tendría que los gramos por almud variaron de 5.874 a 5.696 . Con lo cual el valor de una fanega de maíz habría fluctuado entre 70.488 y 68.352 gramos, con un promedio de 69.420. Considerando esta última cifra se tendría que:

$$
\begin{aligned}
& 1 \text { fanega }=12 \text { almudes }=150,9 \text { libras }=69.420 \text { gramos } \\
& 1 \text { almud }=12,58 \text { libras }=5.785 \text { gramos }
\end{aligned}
$$

Para el Chile del Valle Central del siglo XVIII esta equivalencia a libras correspondió al peso normal para la fanega de trigo, el principal producto de exportación, ${ }^{18}$ de tal modo que no era una equivalencia desusada para un cereal en el medio colonial americano. De hecho corresponde al valor de un tipo de fanega de maíz en el siglo XIX, aún cuando el rango de variación expresado en libras de ésta unidad, según las localidades, estuvo entre 130 y 864 en Venezuela. ${ }^{19}$

Si se aceptan como valores generales para 'todo lo que se compra y vende al peso', probablemente todo lo que se transaba y pesaba 'al por menor', las equivalencias: 1 libra $=16$ onzas, 1 arroba $=25$ libras y 1 libra $=460$ gramos, se tendrían los siguientes valores mas aproximados a las fuentes para los años 1750-51 y 1775 .

17 En 1548 a los indios de la costa de Río Hacha cercana a Venezuela se les daba tres arepas diarias, de las cuales cuatro hacían un almud de maíz, dándoseles con ellas algún pescado. Cada arepa pesaba más o menos una libra, según pesaje efectuado por el escribano. Véase Saldarriaga E., Gregorio: "La inserción del maíz en el gusto de la sociedad colonial del Nuevo Reino de Granada", Historia y Sociedad, núm. 6, págs. 94-95.

18 De Ramón, J. y Larraín, J. M.: Orígenes de la vida económica chilena. 1659-1808, CEP, Chile, 1982, pág. 377.

19 Almenar, Consultor..., pág. 45. 


\section{Cuadro N. ${ }^{\circ} 2$}

RELACIONES DE EQUIVALENCIA ENTRE MEDIDAS ANTIGUAS Y MODERNAS SEGÚN PRODUCTOS EN LA SEGUNDA MITAD DEL SIGLO XVIII. PROVINCIA DE CARACAS

\begin{tabular}{|c|c|c|}
\hline Producto & Equivalencias antiguas & Equivalencias modernas \\
\hline \multirow[t]{2}{*}{ Maíz } & 1 fanega $=12$ almudes $=150$ libras & 1 fanega $=69.000$ gramos \\
\hline & 1 almud = 12,5 libras & 1 almud $=5.750$ gramos \\
\hline \multirow[t]{2}{*}{ Granos } & 1 fanega $=12$ almudes $=144$ libras & 1 fanega $=66.240$ gramos \\
\hline & 1 almud $=12$ libras & 1 almud $=5.520$ gramos \\
\hline Casabe & 1 arroba $=25$ libras & 1 arroba $=11.500$ gramos \\
\hline Cacao & $\begin{aligned} 1 \text { fanega } & =110 \text { libras }=1.760 \text { onzas } \\
1 \text { libra } & =16 \text { onzas }\end{aligned}$ & $\begin{aligned} 1 \text { fanega } & =50.600 \text { gramos } \\
1 \text { onza } & =28,75 \text { gramos }\end{aligned}$ \\
\hline Carne & 1 arroba $=25$ libras & $\begin{aligned} 1 \text { arroba } & =11.500 \text { gramos } \\
1 \text { onza } & =28,75 \text { gramos }\end{aligned}$ \\
\hline \multirow[t]{2}{*}{ Papelón } & 1 arroba $=25$ libras & 1 arroba $=11.500$ gramos \\
\hline & 1 fanega $=150$ libras $=6$ arrobas & 1 fanega $=69.000$ gramos \\
\hline
\end{tabular}

\section{Algunos problemas de cálculo de consumo de alimentos: cantidad de población.}

La importancia del documento de 1752 radica en que presenta cifras y una metodología para el cálculo del consumo de varios alimentos, con los correspondientes valores por unidades territoriales eclesiásticas. Consta de dos partes: una, en la que se presentan los datos de población del año 175051 de la gobernación de Venezuela en dos cuadros, según matrículas por vicarías. Para el cálculo de la población de la gobernación se habrían utilizado informaciones demográficas procedentes de los registros o 'matrículas' elaboradas por los párrocos del Obispado de Caracas. Esta circunscripción eclesiástica, subdividida en 'vicarías' que comprendían un cierto número de 'parroquias', abarcaba a fines del período colonial un área equivalente al $20 \%$ del actual territorio nacional, en el que se localizaba el 60 $\%$ de la población total, con la mitad del total de caseríos, aldeas, poblados y ciudades. ${ }^{20}$

Y consta de otra parte, en la que se proporcionan los cálculos de consumo de víveres correspondientes a cada una de las vicarías, en una Tabla

20 Lombardi, J.V.: People and places in colonial Venezuela, Indiana University Press, Bloomington, 1975, pág. 27. 
de consumo de carne y otra que presenta el consumo general de varios víveres.

Los datos de población presentan varias inconsistencias. La suma de la población de las 18 vicarías en la primera tabla (folio 1) es incorrecta, pues su valor es 144.796 y no 179.716 como se presenta en el documento. Asimismo, los valores parciales de población y algunos totales, por cada vicaría, no coinciden con los de algunas unidades territoriales de la segunda tabla (folio 2). La suma de la población total es idéntica, sin embargo, en ambas tablas documentales.

Para una reconstrucción coherente de los valores de población se ha supuesto que son correctas las cifras parciales de población correspondientes a la segunda tabla. No obstante, el total de población de ésta es incorrecto. Corregido este total da un valor de 182.166 'almas' y no 179.716 como considera el documento. El cálculo del número de "párvulos" en esta segunda tabla también es inexacto, si nos atenemos al valor de $17 \%$ aceptado por el autor. En particular estos valores son incorrectos para el Tuy, Aragua, Nirgua, Araure, Guanare, Barquisimeto y Coro. En el documento se calcula el número de párvulos aplicando ese porcentaje en 11 de los 18 casos considerados, lo que indicaría que se lo utilizó como un parámetro. La categoría de 'párvulo' y de 'adulto' corresponden aquí a una dicotomía resultado de aplicar a la población total el criterio de la responsabilidad religiosa, el que establecía que a partir de los siete años se requería observar los sacramentos, siendo los párvulos los que tenían menos de esa edad. ${ }^{21}$ Hechas las correcciones, el total de párvulos es de 30.967 y no de 30.648. Respecto a la confiabilidad del parámetro de población de menos de seis años, $17 \%$, es poco lo que se puede decir. Se sabe que entre 1800 y 1809 ese segmento de la población alcanzaba el $27,96 \%$, cuando la población promedio alcanzaba los 427.205 personas. ${ }^{22}$ Sin embargo, parece un valor razonable si se considera que en la población venezolana de 1753 a 1798 el grupo etario de 0 - 4 años de edad constituyó $16,5 \%$ de la población total y el de $5-9$, un $17,2 \% .{ }^{23}$

El total documental de 'Adultos' de la segunda tabla también está mal calculado, pues la suma es de 151.199 y no de 149.183. Los valores documentales son erróneos para Caracas, Tuy, Aragua, San Luis de Cura, Nirgua, Araure, Guanare y Barquisimeto. La población total, incluyendo

21 Ibídem, págs. 35 y 41.

22 Ibídem, pág. 132, tabla A-1; y pág. 137, tabla A-10.

23 Almécija, J.: La familia en la Provincia de Venezuela, 1745-1798, Madrid, 1992, pág. 195, tabla 4. 
párvulos y adultos, habría sido de 182.166 personas, cifra que no difiere demasiado del número total de 184.000 que el documento asigna, "sin error alguno", al considerar una "matrícula' faltante de algunos pueblos del Partido de San Felipe cuyo número alcanzaría unas 3.400 personas, según el autor del documento.

En todo caso, para ser más exacto lo anterior significaría, por una parte, que el total de la población sin omisiones de matrículas habría alcanzado unas 185.566 personas, considerando el total del cuadro número 3. Y, por otra, que el concepto 'adultos' incluiría a individuos de las distintas etnias. Se advierte que para calcular la estructura corregida de la población total se ha asumido que el parámetro documental de párvulos es correcto.

\section{CUAdRo N. ${ }^{\circ} 3$}

POBLACIÓN DE LA PROVINCIA DE CARACAS: 1751 (VALORES CORREGIDOS)

\begin{tabular}{lrrr}
\multicolumn{1}{c}{ Vicarías } & Adultos & Párvulos & Total \\
\hline Caracas $\quad 21.862$ & 4.478 & 26.340 \\
$\quad \quad \quad$ Ciudad & & & 18.008 \\
Guarenas & & & 8.332 \\
La Guaira & 6.201 & 1.270 & 7.471 \\
Valles del Tuy & 4.719 & 966 & 5.685 \\
Villa de Aragua & 4.963 & 1.017 & 5.980 \\
Valle de San Luis de Cura & 16.097 & 3.297 & 19.394 \\
San Sebastián de los Reyes & 917 & 188 & 1.105 \\
Valencia & 11.640 & 2.384 & 14.024 \\
Nirgua & 12.433 & 2.546 & 14.979 \\
Villa de San Carlos & 4.392 & 900 & 5.292 \\
Villa de Araure & 6.672 & 1.366 & 8.038 \\
Ciudad de Guanare & 3.742 & 767 & 4.509 \\
Ciudad de San Felipe & 7.805 & 1.599 & 9.404 \\
Ciudad de Barquisimeto & 8.482 & 1.737 & 10.219 \\
Ciudad de Carora & 7.464 & 1.529 & 8.993 \\
Ciudad de Tocuyo & 6.143 & 1.258 & 7.401 \\
Ciudad de Trujillo & 7.906 & 1.619 & 9.525 \\
Ciudad de Coro & 7.708 & 1.578 & 9.286 \\
\hline Total & 12.053 & 2.468 & 14.521 \\
\hline
\end{tabular}


Es importante advertir que la designación de las unidades territoriales de localización de la población del primer documento corresponde con la enumeración de lugares del documento de 1775, aunque éste no las designe propiamente tal como 'vicarías'. En ambas fuentes Caracas está diferenciada como recinto urbano y área colindante externa: "Pueblos y parajes de sus contornos" en 1751, y "Pueblos de sus contornos" en 1775. El único lugar nombrado de un modo levemente distinto corresponde al área del principal puerto: "Puerto de la Guaira y su costa" en 1751 y "Costa de la mar con la Guaira y Catia" en 1775.

\section{Problemas de cálculo del consumo de carne}

El cálculo de consumo de carne requiere precisar cuantitativamente las variables 'consumo anual de reses', 'población consumidora de carne' y 'carne utilizable'. En las fuentes utilizadas el consumo de carne se evalúa por la cantidad de reses sacrificadas anualmente, lo que introduce un sesgo para precisar la cantidad de proteína animal en la dieta diaria.

Es sabido que la cantidad de carne disponible para alimentación por res no es igual al peso de una res, dado que éste incluye también el de los huesos, vísceras, cuero, cachos, pezuñas y rabo. El concepto que interesa aquí es el de 'carne utilizable', que equivale a un porcentaje del peso total o peso 'en canal', y más específicamente, la cantidad media de carne utilizable por persona. Se ha calculado en base a las siguientes fórmulas:

1. Consumo per cápita total $=$ consumo anual de carne utilizable $/$ población consumidora.

2. Consumo diario medio per cápita $=$ consumo per cápita total $/ 365$ días.

Dejando de lado los problemas insolubles de conocimiento y construcción de los datos básicos documentales, una primera cuestión es la del peso medio de las reses. Todas las fuentes utilizadas, mencionan la cifra de 14 arrobas por animal para el período colonial y de 18 arrobas para el siglo XIX. Parecen verosímiles estos valores de peso medio por res, si se considera que en el período colonial, a mediados del siglo XVIII, todavía no se incorporaban plenamente a la producción ganadera los reservorios de la región apureña, rica en pastos, cuyas reses podrían haber tenido un mayor peso medio. Distintos observadores han señalado que, 
durante el siglo XIX y primeros decenios del XX, los ganados del Apure conducidos al Táchira y Barinas tenían un peso medio entre 18 y 20 arrobas. En cambio, el ganado llanero propio de las áreas centrales fluctuaba entre las 13 y 14 arrobas por animal, ${ }^{24}$ precisamente aquél que podría haber abastecido las regiones centro costeras más pobladas hasta fines del siglo XVIII.

Respecto al cálculo del consumo de carne, el primer documento señala en el folio dos el número de 13.500 reses conducidas anualmente a las vicarías de Caracas, Guarenas y La Guaira, para un promedio de 14 arrobas de carne por res. En el folio tres el cálculo lo realiza sobre la base de 31.500 reses anuales. Como en su tabla tercera de la misma hoja emplea sistemáticamente esta última cifra, se ha supuesto que ésta es correcta. El parámetro de 14 arrobas por res "de carne así seca como fresca" del folio dos, se sobrentiende documentalmente como carne 'utilizable', pero corresponde al peso medio del ganado llanero o criollo que, según algunos tratadistas, lo caracterizaría hasta el siglo XX. ${ }^{25} \mathrm{Si}$ esta observación es correcta, se deduciría que en el documento no se descuentan los 'desperdicios' de la res (vísceras, cachos, patas, rabo, cuero y cola). Las cifras de la tercera tabla del documento no divergen demasiado de las cifras corregidas que se presentan en el cuadro 4.

La modalidad documental de cálculo de las personas que comían carne, suma a mitad de los párvulos al número de 'adultos' de la segunda tabla, "por que éstos también comen carne y beben chorote", apreciación que parece realista si se atiende a los antecedentes que se tienen de las costumbres alimenticias coloniales. ${ }^{26} \mathrm{El}$ total excluye a "los soldados de la tropa y la gente de mar", valor que parece adecuado para el autor del documento pues "se evidencia que aunque se asignaron $3.600=$ reses para el consumo o abasto anual en las predichas partes, atendiendo a que se ha aumentado el número de gente con la tropa, no sería desproporción fuera de cómputo prudencial". En nuestra interpretación, el texto plantearía que, aún sin sumar las 3.600 reses que abastecían el consumo de la tropa, la no consideración de éstas en el total de reses calculado no afectaría a la verosimilitud de este valor total.

24 Torres, J.: "Régimen alimenticio y nutrición en algunos hatos del Alto Apure (Venezuela): un estudio cuantitativo, 1909-1910”, Anuario de Estudios Americanos, LVII-1, Sevilla, 2000, págs. 270-271.

25 Torres, "Régimen..., tabla II, págs. 270-271.

26 Torres, "Consumo de carne...”, pág. 68. 


\section{CUADRO N. ${ }^{\circ} 4$}

NÚMERO DE CONSUMIDORES DE CARNE. PROVINCIA DE CARACAS:

1750-51 (VALORES CORREGIDOS)

\begin{tabular}{lrrr} 
Vicarías & Adultos & Párvulos & Total \\
\hline Caracas & 21.862 & 2.239 & 24.101 \\
Guarenas & 6.201 & 635 & 6.836 \\
La Guaira & 4.719 & 483 & 5.202 \\
Valles del Tuy & 4.963 & 509 & 5.472 \\
Villa de Aragua & 16.097 & 1.649 & 17.746 \\
Valle de San Luis de Cura & 917 & 94 & 1.011 \\
San Sebastián de los Reyes & 11.640 & 1.192 & 12.832 \\
Valencia & 12.433 & 1.273 & 13.706 \\
Nirgua & 4.392 & 450 & 4.842 \\
Villa de San Carlos & 6.672 & 683 & 7.355 \\
Villa de Araure & 3.742 & 384 & 4.126 \\
Ciudad de Guanare & 7.805 & 800 & 8.605 \\
Ciudad de San Felipe & 8.482 & 869 & 9.351 \\
Ciudad de Barquisimeto & 7.464 & 765 & 8.229 \\
Ciudad de Carora & 6.143 & 629 & 6.772 \\
Ciudad de Tocuyo & 7.906 & 810 & 8.716 \\
Ciudad de Trujillo & 7.708 & 789 & 8.497 \\
Ciudad de Coro & 12.053 & 1.234 & 13.287 \\
\hline Total & 151.199 & 15.487 & 166.686
\end{tabular}

Para calcular el número de reses consumidas, el documento utiliza el valor anual "conocido" de 31.500 reses que abastecían el mercado de las tres primeras áreas o localidades, equivalente a 441.000 arrobas. Al parecer, el autor supone que ese número de animales era el que efectivamente ingresaba a ese mercado.

Dividido este total por la población consumidora proporciona el parámetro 12,202883 que el autor aplica a los restantes valores conocidos de población, obteniendo así las cifras del número de reses consumidas en cada localidad. La variable 'número de reses', por tanto, fue obtenido sobre el supuesto de que el consumo per cápita medio para la Gobernación corresponde al de las localidades de Caracas, Guarenas y La Guaira. 
Probablemente esto sea cierto para esas tres localidades, pero no lo es para otras áreas predominantemente ganaderas del interior en donde este valor pudo ser mayor. En todo caso no se dispone de evidencias para refinar este promedio. Además, el documento también asume que cada res proporciona 14 arrobas de carne 'consumible' lo que, como se ha dicho, no es efectivo. Así, el documento identifica reses ingresadas al mercado con carne utilizable y consumida.

Es importante también advertir que el consumo per cápita documental corresponde a un 'consumo total anual', a partir del cual se calcula después el consumo per cápita diario. La variable 'consumo per cápita diario' es, por tanto, dependiente, lo que permite modificar los valores de la variable 'número de días'. En el cuadro número 5 de la página siguiente, se proporcionan los valores del 'número de reses' y 'carne consumida' por localidad, de acuerdo a una cifra de 'carne utilizable' de un $50 \% .{ }^{27}$ El 'número de reses' por vicaría es igual a la 'población consumidora' de carne de res multiplicada por 12,202883 y dividida por 14. La variable 'carne utilizable' es igual al 'número de reses' multiplicado por 14 y dividido por 2 . El documento no consideró el consumo de carne de res en la ciudad de Carora debido a que "tiene fundado su abasto en la carne de cabra, así fresca como seca". Por eso tales valores no se han considerado en este cuadro. Como se advierte, el total corregido del número de reses total difiere en 1,4\% del total de la fuente.

El procedimiento documental para obtener la carne consumida calcula, por una parte, el 'consumo total de carne per cápita anual' de las tres primeras vicarías multiplicando el número de reses por el peso medio de cada una, dividiendo el resultado por el número de personas consumidoras. Al dividir el 'consumo total de carne per cápita anual' por el número de días de consumo anual se obtiene el 'promedio de consumo per cápita diario' de una libra y siete onzas, unos 652,6 gramos, para un total anual de 215 días de consumo. Pero si se utilizan las cifras corregidas de población y de carne utilizable, se tendría que el 'consumo anual per cápita de carne' sería de 152,5 libras y el 'consumo medio per cápita diario' de 0,709 libras, 326,4 gramos, para 215 días de consumo o 192,2 gramos diarios per cápita para 365 días.

En relación al consumo de carne en 1775 (véase la tabla I en el apéndice final) la fuente señala que "haciendo todo un cuerpo y los desperdicios

27 Torres, "Consumo de carne...". 
considero a cada persona según lo que he visto 14 onzas por cabeza chico con grande, a este respecto son 13 arrobas al año por cabeza", ${ }^{28}$ no excluyendo ni a indios ni a muchachos. Podría interpretarse este texto como asumiendo que cada persona consumiría casi una res anual, de la que se ha considerado sólo su peso en canal. La carne consumida sería así sólo el $50 \%$ de la cifra documental.

\author{
CUADRO N. ${ }^{\circ} 5$ \\ NÚMERO DE RESES Y CARNE CONSUMIDA. PROVINCIA DE CARACAS: \\ 1751 (VALORES CORREGIDOS)
}

\begin{tabular}{lrrr}
\multicolumn{1}{c}{ Vicarías } & $\begin{array}{c}\text { Población } \\
\text { consumidora }\end{array}$ & N. $^{\text {o }}$ de reses & $\begin{array}{c}\text { Carne consumida } \\
\text { (arrobas) }\end{array}$ \\
\hline Caracas & 24.101 & 21.007 & 147.049 \\
Guarenas & 6.836 & 5.958 & 41.706 \\
La Guaira & 5.202 & 4.534 & 31.738 \\
Valles del Tuy & 5.472 & 4.770 & 33.390 \\
Villa de Aragua & 17.746 & 15.468 & 108.276 \\
Valle de San Luis de Cura & 1.011 & 881 & 6.167 \\
San Sebastián de los Reyes & 12.832 & 11.185 & 78.295 \\
Valencia & 13.706 & 11.947 & 83.629 \\
Nirgua & 4.842 & 4.220 & 29.540 \\
Villa de San Carlos & 7.355 & 6.411 & 44.877 \\
Villa de Araure & 4.126 & 3.596 & 25.172 \\
Ciudad de Guanare & 8.605 & 7.500 & 52.500 \\
Ciudad de San Felipe & 9.351 & 8.151 & 57.057 \\
Ciudad de Barquisimeto & 8.229 & 7.173 & 50.211 \\
Ciudad de Carora & - & - & \\
Ciudad de Tocuyo & 8.716 & 7.597 & 53.179 \\
Ciudad de Trujillo & 8.497 & 7.406 & 51.842 \\
Ciudad de Coro & 13.287 & 11.581 & 81.067 \\
\hline Total & 159.914 & 139.385 & 975.695
\end{tabular}

28 Marón, “Relación...”, págs. 447 y 448. 
El cálculo del consumo por lugar efectuado por la misma fuente presenta otros problemas. Si bien éstos aceptan explícitamente las cifras de 14 onzas al día por cabeza como equivalentes a 13 arrobas al año, las cifras de consumo en arrobas en su casi totalidad corresponden a una relación de 14 arrobas per cápita anual. Según ello, una arroba equivaldría a 365 onzas, equivalencia distinta a la de 393 asumida en los promedios que enuncia la fuente. Por tanto, hay una relación documental fluctuante en la equivalencia de arrobas en onzas. En las cifras corregidas que se presentan en el cuadro número 7 se ha tomado como base de cálculo la cifra per cápita diaria de 14, cifra considerada más segura, y a este consumo total por 'vicaría' se le ha aplicado la equivalencia moderna de arroba a onzas del cuadro número 2. Esto significa que se ha considerado un consumo anual per cápita de 12,775 arrobas como parámetro a aplicar a la población consumidora cuya cifra resultante de consumo por localidad se ha redondeado elevando a la unidad su primer decimal.

\section{Problemas de cálculo del consumo de otros víveres.}

Para el maíz y el casabe el documento de 1751 calcula 33,1818 almudes per cápita anuales, es decir 2,76515 fanegas, de acuerdo a un consumo de tres arepas diarias. Pero como "Lo regular es que a un peón de trabajo, cuando no le dan el pan de maíz le dan una torta y media de casabe por ración al día y es una libra", a cada uno le correspondería sólo la mitad de esta cantidad. De acuerdo al cuadro número 2 de equivalencias adoptadas, eso significa que el maíz era consumido a razón de 261,36 gramos diarios por persona para un año base de 365 días. A su vez, como el casabe era asignado a razón de una libra diaria por peón, el tener que compartirlo con el maíz obliga a considerar sólo media libra por persona en un período de 365 días, lo que significa 230 gramos per cápita diario.

Las estimaciones documentales de ambos consumos se hacen sobre la base de la observación de que la distribución por regiones de éstos era variable, pues en la valles de la Costa tenía prioridad el consumo de casabe y plátanos, que en cambio no se consumía en Carora, Tocuyo y Barquisimeto. Se deduciría, por tanto, que el maíz era un alimento generalizado fuera de los valles costinos. Y de que la población consumidora era la misma que consumía la carne de res. 
En materia de 'granos', los frijoles y las caraotas eran "comunes en toda la Provincia" y el arroz, chícharos, arvejas y otros se consumían "sólo en Caracas y tal cual lugar principal ... y esto entre la gente de mayor distinción”. El procedimiento de cálculo del documento es el siguiente:

1. De 365 días del año, 215 son de consumo de carne y 150 días corresponderían a los granos.

2. Cincuenta personas comen un almud diario de granos. Por tanto, de acuerdo a las equivalencias aceptadas, una persona comería 110,4 gramos diarios, lo que en 150 días corresponde un total de 3 almudes, es decir, 16.560 gramos.

3. Debido a que "no todos los comen" y a que "los caminantes los llevan parbo [¿salvo?] por mitad", un peón comería uno y medio almudes, unos 8.280 gramos diarios, en esos 150 días. Cifra documental que equivale a 22,68 gramos diarios per cápita para un año de 365 días.

El cacao, no obstante "que es el sustento más común desde el más rico al más pobre y desde el más anciano hasta el párvulo", y "que en algunos lugares es más el consumo por lo mucho que le usan", se le asigna una onza diaria por persona, es decir, 28,75 gramos.

En general, el documento utiliza la misma metodología para calcular el consumo de un bien:

1. Cantidad consumida del bien / número de consumidores $=$ consumo per cápita del bien.

2. Consumo per cápita del bien / número de días de consumo = consumo per cápita diario del bien.

Para calcular la cantidad consumida total de un bien en un año utiliza la metodología inversa a partir del consumo per cápita diario. Es la que se ha usado para calcular los valores del cuadro número 6 de la página siguiente, adaptándola a los cambios de unidades.

1. Consumo per cápita diario $(\mathrm{grs}) \times$ número de días $=$ consumo per cápita total (grs)

2. Consumo per cápita total (grs.) / grs. por unidad antigua $=$ consumo per cápita total (unidad antigua)

3. Consumo per cápita total (unidad antigua) $\times$ número de consumidores $=$ cantidad total del bien en el período en unidades antiguas. 
Se han reelaborado los datos de consumo de alimentos en el documento de 1775 para posibilitar su comparación con las distintas variables corregidas de 1751, los que se presentan en el cuadro número 7. Los valores de las variables de éste difieren de las presentadas en la fuente. Para el cacao el documento estipula un consumo diario por persona de una onza, lo que daría una equivalencia de 22,8125 onzas por libra. La fuente lo ha aproximado a 23 libras anuales de consumo. Para el cálculo se ha asumido como observación más segura el valor diario por persona y se ha aplicado el parámetro de 22,8125 para evitar sesgos al convertir los valores en libras a fanegas.

\author{
CUADRO N. ${ }^{\circ} 6$ \\ CONSUMO DE ALIMENTOS. PROVINCIA DE CARACAS: \\ 1751 (VALORES CORREGIDOS)
}

\begin{tabular}{lrrrrrr}
\multicolumn{1}{c}{ Vicarías } & $\begin{array}{c}\text { Población } \\
\text { consumidora }\end{array}$ & $\begin{array}{c}\text { Carne } \\
\text { (arrobas) }\end{array}$ & $\begin{array}{c}\text { Maíz } \\
\text { (fanegas) }\end{array}$ & $\begin{array}{c}\text { Casabe } \\
\text { (arrobas) }\end{array}$ & $\begin{array}{c}\text { Granos } \\
\text { (fanegas) }\end{array}$ & $\begin{array}{c}\text { Cacao } \\
\text { (fanegas) }\end{array}$ \\
\hline Caracas & 24.101 & 147.049 & $33.320,9$ & $175.937,3$ & $3.011,9$ & $4.998,2$ \\
Guarenas & 6.836 & 41.706 & $9.451,2$ & $49.902,8$ & 854,3 & $1.417,7$ \\
La Guaira & 5.202 & 31.738 & $7.192,1$ & $37.974,6$ & 650,1 & $1.078,8$ \\
Tuy & 5.472 & 33.390 & $7.565,3$ & $39.945,6$ & 683,9 & $1.134,8$ \\
Aragua & 17.746 & 108.276 & $24.534,8$ & $129.545,8$ & $2.217,8$ & $3.680,3$ \\
San Luis & 1.011 & 6.167 & $1.397,8$ & $7.380,3$ & 126,3 & 209,7 \\
San Sebastián & 12.832 & 78.295 & $17.740,9$ & $93.673,6$ & $1.603,7$ & $2.661,2$ \\
Valencia & 13.706 & 83.629 & $18.949,3$ & $100.053,8$ & $1.712,9$ & $2.842,4$ \\
Nirgua & 4.842 & 29.540 & $6.694,3$ & $35.346,6$ & 605,1 & $1.004,2$ \\
San Carlos & 7.355 & 44.877 & $10.168,7$ & $53.691,5$ & 919,2 & $1.525,3$ \\
Araure & 4.126 & 25.172 & $5.704,4$ & $30.119,8$ & 515,6 & 855,7 \\
Guanare & 8.605 & 52.500 & $11.896,9$ & $62.816,5$ & $1.075,4$ & $1.784,6$ \\
San Felipe & 9.351 & 57.057 & $12.928,3$ & $68.262,3$ & $1.168,6$ & $1.939,3$ \\
Barquisimeto & 8.229 & 50.211 & $11.377,1$ & $60.071,7$ & $1.028,4$ & $1.706,6$ \\
Carora & $6.772 *$ & & $9.362,7$ & $49.435,6$ & 846,3 & $1.404,4$ \\
Tocuyo & 8.716 & 53.179 & $12.050,4$ & $63.626,8$ & $1.089,3$ & $1.807,6$ \\
Trujillo & 8.497 & 51.842 & $11.747,6$ & $62.028,1$ & $1.061,9$ & $1.762,2$ \\
Coro & 13.287 & 81.067 & $18.370,0$ & $96.995,1$ & $1.660,5$ & $2.755,5$ \\
\hline Total & 166.686 & 975.695 & $230.452,7$ & $1.216 .807,8$ & $20.831,2$ & $34.568,6$ \\
\cline { 2 - 6 }$*$ Esta cifra debe restarse al total para el cálculo de consumo de carne según el cuadro N. 4.
\end{tabular}


Se advierte que el documento utiliza un procedimiento de estimación por el cual el consumo de un bien es función del producto del consumo per cápita diario y anual multiplicado por el número de habitantes. Los datos para 1775 son lo únicos que proporcionan el consumo de sal por persona. Este consumo plantea problemas, puesto que para la información proporcionada en fanegas no se dispone de equivalencias seguras. Al utilizar la equivalencia: 1 fanega $=12$ almudes $=120,5$ libras $=55,43$ kilogramos establecida hacia $1801^{29}$ el consumo per cápita diario sería de 12,66 gramos.

\section{CUADRO N. ${ }^{\circ} 7$}

CONSUMO DE ALIMENTOS. PROVINCIA DE CARACAS: 1775

(cifras corregidas)

\begin{tabular}{|c|c|c|c|c|c|c|c|c|c|}
\hline Vicaría & $\begin{array}{l}\text { Población } \\
\text { consumidora }\end{array}$ & $\begin{array}{l}\text { Carne } \\
\text { (arrobas) }\end{array}$ & $\begin{array}{c}\text { Maíz } \\
\text { (fanegas) }\end{array}$ & $\begin{array}{l}\text { Casabe } \\
\text { (arrobas) }\end{array}$ & $\begin{array}{c}\text { Granos } \\
\text { (fanegas) }\end{array}$ & $\begin{array}{c}\text { Cacao } \\
\text { (fanegas) }\end{array}$ & $\begin{array}{l}\text { Papelón } \\
\text { (fanegas) }\end{array}$ & $\begin{array}{c}\text { Arroz } \\
\text { (fanegas) }\end{array}$ & $\begin{array}{c}\text { Sal } \\
\text { (fanegas) }\end{array}$ \\
\hline Caracas & 29.517 & 188.540 & 56.574 & 236.136 & 9.839 & 6.121 & 9.839 & 9.839 & $2.459,75$ \\
\hline Guarenas & 8.528 & 54.473 & 16.345 & 68.224 & 2.843 & 1.769 & 2.843 & 2.843 & 710,66 \\
\hline Cordillera y Valles del Tuy & 7.015 & 44.808 & 13.445 & 56.120 & 2.338 & 1.455 & 2.338 & 2.338 & 584,58 \\
\hline Valles de Aragua & 19.540 & 124.812 & 37.452 & 156.320 & 6.513 & 4.052 & 6.513 & 6.513 & $1.628,33$ \\
\hline La Guaira, Catia y costa & 6.184 & 39.500 & 11.853 & 49.472 & 2.061 & 1.283 & 2.061 & 2.061 & 515,33 \\
\hline Villa de Cura & 2.028 & 12.954 & 3.887 & 16.224 & 676 & 421 & 676 & 676 & 169,00 \\
\hline San Sebastián y los llanos & 14.281 & 91.220 & 27.372 & 114.248 & 4.760 & 2.962 & 4.760 & 4.760 & $1.190,08$ \\
\hline Valencia y costa & 15.886 & 101.472 & 30.448 & 127.088 & 5.295 & 3.295 & 5.295 & 5.295 & $1.323,83$ \\
\hline Nirgua y valles & 5.292 & 33.803 & 10.143 & 42.336 & 1.764 & 1.098 & 1.764 & 1.764 & 441,00 \\
\hline San Carlos y llanos & 11.129 & 71.087 & 21.331 & 89.032 & 3.710 & 2.308 & 3.710 & 3.710 & 927,41 \\
\hline Araure y llanos & 4.369 & 27.907 & 8.374 & 34.952 & 1.456 & 906 & 1.456 & 1.456 & 364,08 \\
\hline Guanare & 9.540 & 60.937 & 18.285 & 76.320 & 3.180 & 1.979 & 3.180 & 3.180 & 795,00 \\
\hline San Felipe & 10.728 & 68.525 & 20.562 & 85.824 & 3.576 & 2.225 & 3.576 & 3.576 & 894,00 \\
\hline Barquisimeto & 9.315 & 59.500 & 17.854 & 74.520 & 3.105 & 1.932 & 3.105 & 3.105 & 776,25 \\
\hline Carora & 7.628 & 48.724 & 14.620 & 61.024 & 2.543 & 1.582 & 2.543 & 2.543 & 635,66 \\
\hline Tocuyo & 9.525 & 60.841 & 18.256 & 76.200 & 3.175 & 1.975 & 3.175 & 3.175 & 793,75 \\
\hline Trujillo & 9.396 & 60.017 & 18.009 & 75.168 & 3.132 & 1.949 & 3.132 & 3.132 & 783,00 \\
\hline Coro & 14.783 & 94.426 & 28.334 & 118.264 & 4.928 & 3.066 & 4.928 & 4.928 & $1.231,91$ \\
\hline & & & & & & & & & $6.223,62$ \\
\hline
\end{tabular}

29 Landaeta, Riqueza, pág. 221. Esta fuente señala el cahíz de doce fanegas para medir "todo género de granos, la sal y demás cosas secas", precisando en nota al pie que la media fanega equivale a un volumen de 60,25 libras de agua destilada. No se encuentra en el texto de Carlos Almenar ya citado referencia respecto a la equivalencia de la sal. 
Esta cifra difiere significativamente de la de 26,82 conocida hasta el momento y evaluada como "considerablemente alta para la época".$^{30}$ En este último cálculo se emplea la equivalencia señalada por Almenar ${ }^{31} \mathrm{de}$ 1 almud $=9.791$ gramos vigente a fines del siglo XIX.

30 Lovera, José Rafael: Historia de la alimentación en Venezuela, Caracas, 1986, págs. 67 y $81-82$.

31 Almenar, Consultor..., págs. 39, 44. 



\section{Apéndice documental}

[folio 1] Recopilación o Resumen Gral. de las Almas que tiene esta Gobernación de / Venezuela y Caracas según consta de las matrículas del año de 1750 y 51 de / todo el obispado y no obstante de estar hechas matrículas diminutas en algunas / partidas. Empero unas con otras se han conciliado y va este resumen por sus Vicarias / y asimismo va la cuenta de los párvulos que es al fin de calcular el consumo de víve / res en toda ella en cada un año $=$ /

\section{Vicarías}

Caracas y su recinto tiene personas . . . . . . . . . . 18.008

Pueblos y parajes de sus contornos . . . . . . . . . . $8.332 \ldots \ldots .26 .340$

Valles de Guarenas, sus pueblos y anexos $\ldots \ldots \ldots \ldots \ldots \ldots . \ldots . \ldots 771$

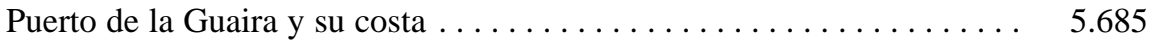

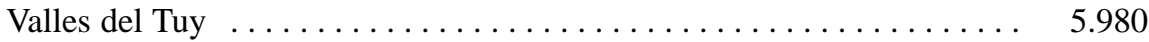

Valles de Aragua y sus pueblos . . . . . . . . . . . . . . . . . . . 17.394

Villa de San Luis de Cura . . . . . . . . . . . . . . . . . . . . . . . 1.105

Ciudad de San Sebastián de los Reyes y sus llanos . . . . . . . . . . . . . 14.024

Ciudad de Valencia y sus valles de la costa . . . . . . . . . . . . . . 14.979

Ciudad de Nirgua y sus valles . . . . . . . . . . . . . . . . . . 5.292

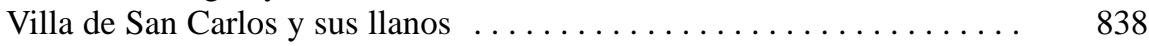

Villa de Araure . . . . . . . . . . . . . . . . . . . . . . . . . 459

Ciudad de Guanare y sus llanos . . . . . . . . . . . . . . . . . . . . . . . . . . . 944

Ciudad de San Felipe sus valles y pueblos . . . . . . . . . . . . . . . . . . . . 1.219

Ciudad de Barquisimeto . . . . . . . . . . . . . . . . . . . . . . . 8.993

Ciudad de Carora . . . . . . . . . . . . . . . . . . . . . . . . . . . . 741

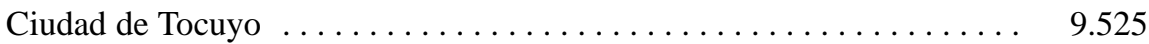

Ciudad de Trujillo sus valles y pueblos . . . . . . . . . . . . . 9.286

Ciudad de Coro sus valles y pueblos . . . . . . . . . . . . . . . . . . . . 14.521

TOTAL .............. 179.716

Suman y montan las diez y ocho partidas de las Vicarias $=179.716=$ almas que se hallan / en toda la Gobernación de Venezuela y Caracas con declaración que faltan de una matrícula / las de los pueblos de Chivacoa, Suaza, Urachiche y su vecindad que es mucha en el Partido de San / Felipe y para el numero de 3.400 personas $=$ con más las matrículas de algunas Misiones. $/$ De suerte que sin error alguno se puede tener por número fijo el de ciento ochenta y cuatro mil / personas de 
todas edades, condiciones y esferas; y aunque algunos tienen concebido que el / número llega a más de 200.000 = se han alucinado metiendo en la cuenta la Vicaría de la ciudad / de Maracaibo por ser de este obispado que pasa el número de sus almas de ciento y diez mil / pues aunque son de este obispado no son de esta Provincia de que se trata, sobre el supuesto de la / referida suma y la proporción que tiene el número de los párvulos a toda la cantidad se tendrá / en el verdadero conocimiento de los víveres que se necesitan para sustento y para entrar / en estos cálculos primero se han de agregar los párvulos del número total y para esto aunque / las matrículas en la mayor parte no hacen distinción sin embargo por las que han venido de / algunas partes con suficiente distinción de su caja la proporción para caminar sobre un / supuesto seguro en este cálculo; y así hecho el examen con debida reflexión resultan / las razones siguientes = / Lo primero que según la comparación de los párvulos con cada número del todo que / le corresponde se hallaron a un 17 = por 100 = próximo, que por no haber venido matrículas / con toda distinción necesaria no se puede creer a punto más fijo que para el cálculo basta, asentan / de esto se sigue el formar nuevo resumen con distinción de cada Vicaría para proceder / con el orden más ajustado que demuestra la tabla siguiente = /

\begin{tabular}{lrrr} 
[folio 2] & Adultos & Párvulos & El todo \\
\hline De Caracas, su recinto, pueblos / & & & \\
inmediatos y parajes en sus / & & & \\
contornos & 21.872 & 4.478 & 26.340 \\
Guarinas idem & 6.201 & 1.270 & 7.471 \\
Guaira y sus valles & 4.719 & 966 & 5.685 \\
Tuy idem & 4.964 & 1.106 & 5.980 \\
Aragua idem & 14.439 & 2.959 & 19.394 \\
San Luis de Cura & 919 & 188 & 1.105 \\
San Sebastián y sus llanos & 11.640 & 2.384 & 14.024 \\
Valencia y sus valles & 12.433 & 2.546 & 14.979 \\
Nirgua idem & 4.393 & 899 & 6.292 \\
San Carlos y sus llanos & 6.672 & 1.366 & 8.038 \\
Araure idem & 3.369 & 690 & 4.509 \\
Guanare idem & 7.806 & 1.598 & 9.404 \\
San Felipe idem & 8.482 & 1.737 & 10.219 \\
Barquisimeto idem & 7.465 & 1.528 & 8.993 \\
Carora idem & 6.143 & 1.258 & 7.401 \\
Tocuyo idem & 7.906 & 1.619 & 9.525 \\
Trujillo idem & 7.708 & 1.578 & 9.286 \\
Coro, sus pueblos y valles & 12.053 & 2.478 & 14.521 \\
\hline TotaL & 149.170 & 30.546 & 179.716
\end{tabular}


Es visto que por esta resulta hay personas adultas ciento cuarenta y nueve mil / ciento y setenta, y hay párvulos treinta mil quinientos cuarenta y seis = Que una y otra partida / hacen el numero de ciento setenta y nueve mil, setecientas y diez y seis personas matriculadas / y respectivamente está ajustado el numero que le corresponde a cada jurisdicción, como se deja ver / en la misma tabla sobre cuyo fundamento se formará el cálculo más exacto que posible sea. / Empero han de proceder otras consideraciones de lo que a cada individuo le pertenece de carne / maíz, cazabe, frijoles y caraotas, cacado cocido que llaman chorote alimento preciso / y muy usual por día o por año $=$ / Se principiará por la carne que se consume anualmente en las Vicarías de Caracas, / Guarenas y la Guaira por conducirse todo el ganado mayor que se consume en dichas / partes a esta ciudad en donde se distribuye y es conocido el numero que es de 13.500 = reses / próximo anualmente que unas con otras se reputan a 14 @ s de carne así seca como / fresca sobre cuyo punto conocido se caminará, de esta suerte, primero se ha de / agregar al número de los adultos, la mitad del número de los párvulos que se hallaren en la / cuenta por que estos también comen carne y beben chorote :

\begin{tabular}{llrr} 
& Son los adultos & 21.862 & \\
Caracas & la mitad de párvulos & 2.239 & 24.101 \\
& Son los adultos & 6.201 & \\
Guarinas & la mitad de los párvulos & 635 & 6.836 \\
& Son los adultos & 4.719 & \\
Guaira & la mitad de párvulos & 483 & 5.202 \\
\hline
\end{tabular}

En conformidad de que la suma de los que comen carne en estas tres vicarías, es la expre / sada cantidad de treinta y seis mil ciento y treinta y nueve personas exceptu / ando los soldados de la tropa y la gente de mar, y así sabido lo que corresponde en dichas / tres partidas se vendrá por la misma práctica en conocimiento del consumo en / cada especie de víveres en cada parte o Vicaría de la Gobernación y sobre ello / se formarán sus respectivos Mapas o Estados en una General para recopilar y dis / tinguir el consumo de cada especie, y ahora se prosigue a computar y repartir / [folio 3] el expresado numero de ganado mayor reducido a @s de carne entre el numero de / los que la comen = / Son pues = $31.500=$ reses que multiplicadas por $14 @$ @ la cantidad de producto es de $/=$ $441.000 @$ s que partida por las = 36.139= personas le toca a cada una 12 @ s y 5 libras / poco más anualmente por aquí se evidencia que aunque se asignaron 
$3.600=$ reses para $/$ el consumo o abasto anual en las predichas partes, atendiendo a que se ha aumentado / el número de gente con la tropa, no sería desproporción fuera de cómputo prudencial $=$ / Para comprobar de lo verídico de este cálculo se pasará a otro cómputo que es como / se sigue $=$ de los 365 días que tiene el año se sacaron los días quadraxecimales, viernes / sábados, vigilias y primeros días de las Témporas, que con corta diferencia son $=150=$ días $/$ y quedan $=$ 215 = de carnal y así a proporción, que a cada individuo le corresponde anualmente $/ 12 @ \mathrm{~s}$ y = 5 = libras poco más que corresponde por día $=1=$ libra y $7=$ onzas (poco menos) que multiplicado / esto por los $=215=$ y reducido su producto a @s salen las 12 @ y 5 libras (poco más) que le / corresponden a cada individuo anualmente = / Para individuar todo lo que toca al consumo general de la Provincia se ha formado / la tabla siguiente, haciendo sumas de los números de los adultos y mitad del número de los / párvulos que es la columna tercera, de los que consumen carne. La cuarta y última colum / na es el número de ganado mayor que a proporción le pertenece a cada vicaría por su / abasto. Y para su inteligencia se multiplica cada artículo de la 3.a columna por el mul / tiplicador común que es $=31.500=$ y el producto se partirá por el partidor común que es / 36.139 de la misma columna $=$ /

\begin{tabular}{|c|c|c|c|c|c|}
\hline \multirow[b]{2}{*}{ Caracas } & \multirow{2}{*}{$\begin{array}{c}\text { Adultos } \\
21.862\end{array}$} & \multicolumn{3}{|c|}{ Mitad de párvulos } & \multirow[t]{2}{*}{ Reses } \\
\hline & & 2.239 & 24.011 & & \\
\hline Guarenas & 6.201 & 635 & 6.836 & 36.139 & 31.500 \\
\hline Guaira & 4.719 & 483 & & 5.202 & \\
\hline Tuy & 4.964 & 508 & & 5.472 & 4.769 \\
\hline Aragua & 14.437 & 1.478 & & 15.915 & 13.872 \\
\hline San Luis & 917 & 94 & & 1.011 & 881 \\
\hline S. Sebastián & 11.640 & 1.192 & & 12.832 & 11.184 \\
\hline Valencia & 12.433 & 1.273 & & 13.706 & 11.946 \\
\hline Nirgua & 4.393 & 449 & & 4.842 & 4.220 \\
\hline San Carlos & 6.672 & 683 & & 7.355 & 6.410 \\
\hline Araure & 3.369 & 345 & & 3.714 & 3.237 \\
\hline Guanare & 7.806 & 799 & & 8.605 & 7.500 \\
\hline San Felipe & 8.482 & 868 & & 9.350 & 8.149 \\
\hline Barquisimeto & 7.465 & 764 & & 8.229 & 7.172 \\
\hline Carora & 6.143 & 629 & & 6.772 & $\ldots$ \\
\hline Tocuyo & 7.906 & 809 & & 8.715 & 7.595 \\
\hline Trujillo & 7.708 & 789 & & 8.497 & 7.406 \\
\hline Coro & 12.053 & 1.234 & & 13.287 & 11.588 \\
\hline TOTAL & 149.170 & 15.271 & & 164.441 & 137.429 \\
\hline
\end{tabular}


Por manera que todo el ganado mayor que se consume en la provincia anualmente llega al número / de ciento treinta y siete mil, cuatrocientas y veinte y nueve reses, y por cada mes $11.452=$ / próximo. Y para mayor explicación de la tabla, queriendo saber qué ganado consume y / y pertenece a Valencia (v.g.a) anualmente se hallará en la margen de la derecha, correspondien / dole $=11.946=$ reses; y correspondientemente en las demás partes no se encuentra con duda $=$ / [folio 4] Se advierte que a la ciudad de Carora no se le ha puesto ganado mayor por que es por / contingente el comerlo, por tener como tiene fundado su abasto en la carne de cabra, / así fresca como seca, acreditándolo la abundancia de los cordobanes que de allí salen así / para toda esta Provincia como para la islas adyacentes y para del nuevo Reino de / Granada = / Por este mismo modo y por indicación sacan los calados de los demás víveres / comunes = / Para proseguir este cálculo, por lo respectivo al maíz, cazabe, frijoles / caraotas que será lo reducible y aun para estos géneros han de preceder las con / sideraciones siguientes. Para caminar sobre un supuesto seguro y demostrable, que / en otra manera será voluntario y sin fundamento bastante $=/$

1. ${ }^{a}$ La primera es que en todos los valles de la Costa es poquísimo el maíz que se gasta lo más / es cazabe y plátanos que suplen por el pan. En Carora, Tocuyo y Barquisimeto / es difícil cosa encontrar con cazabe por que las tierras son demasiado de áridas / viejas y secas para producir la yuca de cuya raíz se hace el cazabe $=1$

2. ${ }^{a}$ La segunda que es evidente que de un almud de maíz producen $=33=$ panes y cada / individuo consume al día $=3=$ de éstos con que se sigue que un almud que es la duodécima / parte de una fanega, dará para cada uno $=11=$ días. Luego divididos los $=365=\mathrm{del}$ año $/$ entre dichos $=11=$ sale al cociente $=33=$ almudes y 2/11 de almud, cuyo quebrado no es de atención / para el cálculo, y así se tiene este número $=33=$ que hacen anualmente $=2=$ fanegas y $9=$ almudes $/$ que son $=3$ = cuartillos de fanega, para el consumo de cada individuo, $\mathrm{y}$ teniendo / presente la consideración antecedente no se puede aplicar a cada uno en general más que la / mitad o poco más correspondiéndole a cada individuo por año $=1=$ fanega y 4 almudes y $1 / 2$ / computando la otra mitad en el artículo del cazabe para que este cálculo corresponda / a el encargo del consumo de estas especies = /

3. ${ }^{\text {a }}$ Asentado esto se pasa a la tercera consideración de esta suerte. Lo regular es que a un / peón de trabajo, cuando no le dan el pan de maíz le dan una torta y media de cazabe / por ración al día y es una libra, en $=25$ = días es una arroba. Luego los = 365 = días del $/$ año partidos por estos = 25=o 1 a @ salen de cociente=14@s 15 libras = por año de esto se / toma la mitad por razón de haber tomado la otra mitad de maíz en el articulo pre / cedente, con que resulta para cada uno anualmente = 7 @ 7 libras y $1 / 2$ de cazabe. Sobre / estos dos fundamentos se formarán los cálculos correspondientes a cada vicaría / como queda practicado con la carne o reses atendiendo que los adultos y mitad de / los párvulos son los que consumen estos géneros $=$ / 


\section{JAIME TORRES SÁNCHEZ}

4. ${ }^{\mathrm{a}}$ La cuarta consideración es que en la misma forma, de por mitad se consumen los / granos de los frijoles y caraotas que son los comunes en toda la Provincia por que / solo en Caracas y tal cual lugar principal se gastan los otros géneros de arroz / chícharos, alverjas etc. $=$ y esto entre la gente de mayor distinción y debiendo / regular el consumo de dichos granos entre cincuenta personas diariamente: un almud / [folio 5] que es como dicho es la duodécima parte de una fanega se halla que cada individuo / consume anualmente en los $=150=$ días con corta diferencia de Cuaresma, viernes, sábados / de etc. 3 = almudes sobre cuyo juicio y prudente consideración formaré el cálculo / de este artículo así en común entre el Ingreso General como en particular / por las vicarías mediante lo cual y el de ser $=164.441=$ personas corresponde $/$ de consumo de dichos granos en el año $=493.323=$ almudes que partidos por 12 hacen $/$ fanegas $=41.110=$ y 3 almudes y habida la consideración de que no todos los comen / por que no los hay así en las costas como en los llanos ni los caminantes los llevan parvo / por mitad y corresponde a $20.555=$ fanegas $=1=$ almud y $1 / 2$ y se tendrá para este $/$ cálculo el número de un almud y medio a cada individuo $=/$

5. ${ }^{a}$ La quinta es del cacao sobre cuyo consumo se han alucinado muchos por / no haber tenido la especulación suficiente y ahora se evidenciará en estos cálculos / el verdadero consumo anual, y lo que corresponde a cada vicaría y jurisdicción / fundando este cálculo sobre experiencia y evidencias, es cierto e innegable / que es el sustento más común desde el más rico al más pobre y desde el más / anciano hasta el párvulo pues el primero manjar que les dan es el cacao con / dulce que llaman chorote; es muy distinto al chocolate en su beneficio, porque / éste es no más que con un tostadillo canela y azúcar, y aquel es pasta cocida con / muy poco agua hasta que levanta el aceite con cuyo beneficio merma mucho / y a cada individuo se le debe asignar una onza generalmente por día no obstante / de que en algunos lugares es más el consumo por lo mucho que le usan en la forma / que el café o el té y este género llaman zerrero, con que sobre el supuesto / de que se asigne generalmente sola una onza de cacao al día para cada indi / viduo se formará el cálculo y tabla en que se pondrá a cada vicaría las canti / dades que corresponden a el número de sus adultos y mitad de párvulos. Y antes / de formar la tabla o mapa hácese el cálculo general o monto del consumo de / este renglón en un año en toda la Gobernación. /

Entre adultos y mitad de párvulos por la tabla antecedente que son / 164.441 $=$ personas que son otras tantas onzas y reducidas a libras $=10.277=/ \mathrm{y} 9=$ onzas diariamente que multiplicadas por $\operatorname{los}=365=$ días del año salen $=3.751 .310=/$ libras $=5=$ onzas que partidas por $=110=$ que tiene la fanega salen por cociente / $34.102=$ fanegas $=90=$ libras $=5=$ onzas de consumo por año $=$ / 
[folio 6]

TABLA DEL RESUMEN GENERAL

\begin{tabular}{|c|c|c|c|c|c|c|c|c|c|c|}
\hline \multirow{2}{*}{$\frac{\text { Pueblos }}{\text { Caracas }}$} & \multirow{2}{*}{$\begin{array}{c}\text { Numero de } \\
\text { reses vacunas } \\
21.008\end{array}$} & \multicolumn{2}{|c|}{$\begin{array}{c}\text { Maíz } \\
\text { Fanegas Almudes }\end{array}$} & \multicolumn{2}{|c|}{ Cazabe } & \multicolumn{2}{|c|}{ Frijoles } & \multicolumn{3}{|c|}{$\begin{array}{r}\text { Cacao } \\
\text { Fanegas Libras }\end{array}$} \\
\hline & & 33.138 & $10^{1 / 2}$ & 175.937 & $71 / 2$ & 3.012 & $71 / 2$ & 4.998 & 24 & 1 \\
\hline Guarenas & 5.958 & 9.399 & 6 & 49.902 & 20 & 854 & 6 & 1.417 & 76 & 4 \\
\hline Guaira & 4.534 & 7.152 & 9 & 37.974 & 15 & 650 & 3 & 1.078 & 90 & 10 \\
\hline Tuy & 4.769 & 7.524 & & 39.945 & 15 & 684 & & 1.134 & 90 & \\
\hline Aragua & 13.872 & 21.883 & $1 \frac{1}{1} 2$ & 116.179 & $12^{1 / 2}$ & 1.989 & $4^{1 / 2}$ & 2.300 & 60 & 15 \\
\hline San Luis & 881 & 1.390 & $1 \frac{1 / 2}{2}$ & 7.380 & $71 / 2$ & 126 & $4^{1 / 2}$ & 209 & 73 & 7 \\
\hline San Sebastián & 11.184 & 17.644 & & 93.673 & 15 & 1.604 & & 2.661 & 20 & \\
\hline Valencia & 11.946 & 18.845 & 9 & 100.053 & 20 & 1.713 & 3 & 2.842 & 48 & 2 \\
\hline Nirgua & 4.220 & 6.657 & 9 & 35.346 & 15 & 605 & 3 & 1.004 & 18 & 2 \\
\hline San Carlos & 6.410 & 10.113 & $1^{1 / 2}$ & 53.691 & $12 \frac{1}{2}$ & 919 & $4^{1 / 2}$ & 1.525 & 35 & 15 \\
\hline Araure & 3.237 & 5.106 & 9 & 27.112 & 5 & 464 & 3 & 770 & 25 & 10 \\
\hline Guanare & 7.500 & 11.831 & $10^{1 / 2}$ & 62.816 & $12 \frac{1}{2}$ & 1.075 & $71 / 2$ & 1.784 & 61 & 9 \\
\hline San Felipe & 8.149 & 12.856 & 3 & 68.255 & & 1.168 & 9 & 1.939 & 6 & 14 \\
\hline Barquisimeto & 7.172 & 11.314 & $10^{1 / 2}$ & 60.071 & $19^{1 / 2}$ & 1.028 & $71 / 2$ & 1.706 & 64 & 1 \\
\hline Carora & & 9.311 & 6 & 49.435 & 15 & 846 & 6 & 1.404 & 46 & 4 \\
\hline Tocuyo & 7.595 & 11.983 & $1 \frac{1 / 2}{2}$ & 63.619 & $12^{1 / 2}$ & 1.089 & $4^{1 / 2}$ & 1.807 & 40 & 15 \\
\hline Trujillo & & 11.683 & 41 & 62.028 & 21 & 1.062 & $1^{1 / 2}$ & 1.762 & 17 & 13 \\
\hline Coro & 11.588 & 18.269 & $71 / 2$ & 96.995 & $2 \frac{1}{2} 2$ & 1.660 & $10^{1 / 2}$ & 2.755 & 59 & 11 \\
\hline SUMAS & 137.429. & 226.106 & $4 \frac{1}{2}$ & 1.200 .419 & $71 / 2$ & 20.555 & $1^{1 / 2}$ & 34.102 & 90 & 5 \\
\hline
\end{tabular}

Es hecha la calculación antecedente por el regidor D. Fernando de / Lovera de orden del Ex.ns Señor D. Felipe Ricardos Teniente General / de los Reales Ejércitos de S. M. actual Gobernador de esta Provincia / de Venezuela. En Caracas a veinte y dos de abril de mil setecientos / cincuenta y dos = [margen derecho Fernando Antonio de Lovera y Otañes (rúbrica) foliar

Archivo General de Indias, Caracas, 368; Caracas, 22 de abril de 1752; sin 


\section{JAIME TORRES SÁNCHEZ}

\section{TABLA I}

\section{CONSUMO DE ALIMENTOS EN LA PROVINCIA DE CARACAS EN 1775}

(cifras documentales corregidas)

\begin{tabular}{lrrrrrrrrr} 
Vicaría & $\begin{array}{c}\text { Población } \\
\text { consumidora }\end{array}$ & $\begin{array}{c}\text { Carne } \\
\text { (arrobas) }\end{array}$ & $\begin{array}{c}\text { Maíz } \\
\text { (fanegas) }\end{array}$ & $\begin{array}{c}\text { Casabe } \\
\text { (arrobas) }\end{array}$ & $\begin{array}{c}\text { Granos } \\
\text { (fanegas) }\end{array}$ & $\begin{array}{c}\text { Cacao } \\
\text { (fanegas) }\end{array}$ & $\begin{array}{c}\text { Papelón } \\
\text { (fanegas) }\end{array}$ & Arroz (fanegas) & $\begin{array}{c}\text { Sal } \\
\text { (fanegas) }\end{array}$ \\
\hline Caracas & 29.517 & 377.080 & 56.574 & 236.136 & 9.839 & 6.121 & 9.839 & 9.839 & $2.459,75$ \\
Guarenas & 8.528 & 108.945 & 16.345 & 68.224 & 2.843 & 1.769 & 2.843 & 2.843 & 710,66 \\
Cordillera y Valles del Tuy & 7.015 & 89.617 & 13.445 & 56.120 & 2.338 & 1.455 & 2.338 & 2.338 & 584,58 \\
Valles de Aragua & 19.540 & 249.624 & 37.452 & 156.320 & 6.513 & 4.052 & 6.513 & 6.513 & $1.628,33$ \\
La Guaira, Catia y costa & 6.184 & 79.001 & 11.853 & 49.472 & 2.061 & 1.283 & 2.061 & 2.061 & 515,33 \\
Villa de Cura & 2.028 & 25.908 & 3.887 & 16.224 & 676 & 421 & 676 & 676 & 169,00 \\
San Sebastián y los llanos & 14.281 & 182.440 & 27.372 & 114.248 & 4.760 & 2.962 & 4.760 & 4.760 & $1.190,08$ \\
Valencia y costa & 15.886 & 202.944 & 30.448 & 127.088 & 5.295 & 3.295 & 5.295 & 5.295 & $1.323,83$ \\
Nirgua y valles & 5.292 & 67.605 & 10.143 & 42.336 & 1.764 & 1.098 & 1.764 & 1.764 & 441,00 \\
San Carlos y llanos & 11.129 & 142.173 & 21.331 & 89.032 & 3.710 & 2.308 & 3.710 & 3.710 & 927,41 \\
Araure y llanos & 4.369 & 55.814 & 8.374 & 34.952 & 1.456 & 906 & 1.456 & 1.456 & 364,08 \\
Guanare & 9.540 & 121.874 & 18.285 & 76.320 & 3.180 & 1.979 & 3.180 & 3.180 & 795,00 \\
San Felipe & 10.728 & 137.050 & 20.562 & 85.824 & 3.576 & 2.225 & 3.576 & 3.576 & 894,00 \\
Barquisimeto & 9.315 & 118.999 & 17.854 & 74.520 & 3.105 & 1.932 & 3.105 & 3.105 & 776,25 \\
Carora & 7.628 & 97.448 & 14.620 & 61.024 & 2.543 & 1.582 & 2.543 & 2.543 & 635,66 \\
Tocuyo & 9.525 & 121.682 & 18.256 & 76.200 & 3.175 & 1.975 & 3.175 & 3.175 & 793,75 \\
Trujillo & 9.396 & 120.034 & 18.009 & 75.168 & 3.132 & 1.949 & 3.132 & 3.132 & 783,00 \\
Coro & 14.783 & 188.853 & 28.334 & 118.264 & 4.928 & 3.066 & 4.928 & 4.928 & $1.231,91$ \\
\hline TotaL & 194.684 & 2.487 .091 & 373.144 & 1.557 .472 & 64.894 & 40.357 & 64.894 & 64.894 & $16.223,62$
\end{tabular}

Fuentes: Marón, A.: "Relación Histórico-Geográfica de la Provincia de Venezuela. 1775", en Arellano Moreno, A., (compilador), Documentos para la Historia Económica Colonial. Viajes e Informes, Caracas, 1970, págs. 411-474. 